\title{
BIBLIOTERAPIA: UMA PROPOSTA PARA ADOLESCENTES INTERNADOS EM ENFERMARIAS DE HOSPITAIS PÚBLICOS
}

\section{Gizele Ribeiro}

\section{Resumo}

Este artigo versa sobre uma proposta de implantação de um programa de Biblioterapia para adolescentes, como coadjuvante de tratamento médico, nas enfermarias de hospitais públicos da Rede Municipal de Saúde do Rio de Janeiro. A proposta nasceu a partir da uma revisão de literatura que apontou a biblioterapia como um processo de cura, de lazer, de estímulo à leitura e, conseqüentemente, de aumento do conhecimento para os adolescentes estimulados durante o período de internação.

\section{Palavras-chave}

Biblioterapia; Adolescentes; Hospitais.

\section{BIBLIOTHERAPY: A PROPOSAL FOR IN-PATIENTS ADOLESCENTS OF PUBLIC HOSPITALS INFIRMARIES.}

\begin{abstract}
It is proposed a project to set up a bibliotherapeutic program for in-patients adolescents, from ten to twelve years old, of public hospitals infirmaries of The Municipal Net of Health of Rio de Janeiro (RJ, Brazil). Biblioteraphy, besides integrating the leisure and cure process during the staying of the adolescent in the hospital, will be able to serve as stimulus to reading; consequently it will increase their knowledge after this period hospitalization.
\end{abstract}

\section{Keywords}

Bibliotherapy; Adolescence; Hospitals. 


\section{INTRODUÇÃO}

Um dos grandes desafios da contemporaneidade é retomar a concepção do Ser Humano dentro das Instituições de Saúde, de modo a trazer o conceito de Humanização para a prática profissional. Humanizar dá idéia de tornar humano algo ou alguém que, essencialmente, já o é, ou o deveria ser, mas que acaba não tendo essa dimensão tão essencial ao convívio social e profissional. Os frutos dessa reflexão foram trazidos para o contexto hospitalar, de forma a melhorar o atendimento nos serviços públicos de saúde. Dentro dessa perspectiva, este artigo sugere um olhar especial para o tratamento com adolescentes em enfermarias, utilizando como instrumento a Biblioterapia. Através da leitura, que permite um aprendizado e uma identificação com o universo por ela apresentado, os limites da realidade são ultrapassados. O paciente, dentro desse processo, se sentirá refeito mentalmente, acarretando um resultado positivo no seu tratamento.

O papel da leitura mediada para a melhoria da qualidade de vida de adolescentes durante o período de internação hospitalar teve sua base na revisão de literatura sobre a aplicabilidade da Biblioterapia, nos últimos cinco anos, oferecendo um panorama geral da leitura inserida no processo de humanização nos hospitais públicos.

A Biblioterapia tem sido uma grande contribuição terapêutica por minimizar os sentimentos de angústia, isolamento, fragilidade física e emocional decorrentes da internação. Ela traz resultados positivos que se refletem na qualidade de vida do indivíduo internado, do acompanhante e da equipe médica. O adolescente sente necessidade de ser livre e o fato de estar preso a um leito de enfermaria passa a ser um pesadelo para ele. Na condição de doente e por causa do tratamento, ele se afasta do lar, da escola e dos amigos. Isso pode acarretar um comportamento de revolta e até de agressividade. A leitura dirigida, oferecida pela Biblioterapia, pode aliviar esses sentimentos e representa uma oportunidade ímpar, pois, além de colaborar no tratamento desse paciente, ela possibilitará a ampliação de seus horizontes e conhecimentos. 
Essa modalidade terapêutica ajuda os pacientes adolescentes a superar o medo, a angústia, a tristeza, o desalento e a ansiedade que acompanham uma doença, contribuindo para a promoção do bem estar e auxiliando a implementação do tratamento, a prevenção de outros males e minimizando os problemas pessoais. Ela colabora, também, no autoconhecimento, no desenvolvimento emocional e na mudança de comportamento, provocado pela retomada do cuidado com o paciente, assim como potencializa a dimensão fraternal do cuidar, do se importar com os outros, do se colocar no lugar do outro. Através de projetos que valorizam a humanização no atendimento de saúde e no cuidado com pacientes hospitalares se espera a realização de todas essas ações citadas.

\section{HUMANIZAÇÃO NOS CUIDADOS COM PACIENTES HOSPITALARES}

Pessini (2004, p. 12) abordou, em seus estudos, a questão da humanização da dor e do sofrimento humano do contexto hospitalar. Nesse ambiente, prevalecem os procedimentos tecnicamente perfeitos, mas sem valorização do emprego da ternura àqueles que ali buscam tratamento. A pessoa, ser humano vulnerável pela doença, deixou de ser o centro das atenções. Pessini aponta, também, a dor e o sofrimento presentes e aborda a necessidade de aliviá-los. O autor chama essa ação de cuidado. Esse cuidado passa a ser o alvo do profissional quando ele se empenha em mudar atitudes arraigadas, por meio da adoção de práticas que promovam a interação entre pacientes e profissionais de saúde tal como ocorre durante uma sessão de Biblioterapia. Intuitivamente, o homem sempre utilizou o livro como recurso para auxiliar no tratamento médico, conforme relatos feitos ao longo da história.

\section{A BIBLIOTERAPIA NA HISTÓRIA}

A Biblioterapia existe desde a Antigüidade. Seu uso, a princípio, se realizava através da leitura de histórias que entretinham crianças, jovens e adolescentes, procurando ocupar o tempo ocioso, até que esse uso foi identificado como instrumento terapêutico, passando, então, a ser utilizado em isolamentos existentes nas prisões, hospitais, manicômios, até os dias de hoje. 
Ferreira (2003, p. 36) declara que o uso da leitura, com objetivo terapêutico, existe desde o antigo Egito, no tempo do faraó Rammsés II, que colocou na frente de sua biblioteca a seguinte frase: "Remédios para alma". As bibliotecas egípcias estavam localizadas em templos denominados "casas de vida" e eram conhecidas como locais de conhecimento e espiritualidade.

Os gregos fizeram associação entre livros e tratamento médico espiritual ao conceberem suas bibliotecas como "a medicina da alma." Aristóteles, em sua obra A Poética, afirmava que o espectador, frente a uma representação teatral, aliviava-se das pressões da vida diária, o que fornecia, a essa modalidade literária, uma função terapêutica.

Durante o Império Romano, a leitura, seguida de discussão das obras de grandes oradores, foi recomendada, como tratamento médico, por Aulus Corenlius Celsius.

Na biblioteca da Abadia de São Gall, na Idade Média, havia a inscrição "Tesouro dos remédios da alma".

No Oriente, o Hospital Al Mansur, em 1272, recomendava a leitura de trechos escolhidos do Alcorão, como parte do tratamento médico (FERREIRA, 2003, p. 36)

Em várias culturas e em épocas distintas, vamos encontrar a leitura como instrumento de auxílio no cuidado da saúde.

Em 1802, Benjamin Rusch foi o primeiro norte-americano a recomendar a leitura para doentes de um modo geral e, em 1810, recomendou a Biblioterapia como apoio à psicoterapia para pessoas portadoras de conflitos internos, depressão, medos ou fobias, assim como para idosos.

Na década de 30, do século XX, a Biblioterapia passou a ser vista como um campo de pesquisa. Destacaram-se as biblioterapeutas Isabel Du Boir e Emma T. Foremman, que se empenharam para que a Biblioterapia fosse vista como ciência e não como arte (FERREIRA, 2003, p. 37). 
A pesquisadora Ilse Bry publicou, em 1942, um trabalho intitulado "Os aspectos médicos da literatura: um esboço bibliográfico". Sofie Lazarsfeld publicou, em 1949, "O uso da ficção na psicoterapia" que descrevia a reação dos pacientes diante da leitura, reforçando assim a necessidade de auto-análise daqueles que pretendiam trabalhar com a Biblioterapia (FERREIRA, 2003, p. 37).

\section{CONCEITOS DE BIBLIOTERAPIA}

Caroline Shrodes, em 1949, foi a primeira PHD em Biblioterapia e sua tese intitulada "Biblioterapia um estudo teórico e clínico experimental" lançou as bases da Biblioterapia atual, sendo, por esse motivo, muito referenciada entre os autores que tratam do tema. Ela definiu Biblioterapia como a prescrição de materiais de leitura que auxiliam o desenvolvimento da maturidade e que nutrem e mantêm a saúde mental. Incluiu na Biblioterapia publicações como: romances, poesias, peças teatrais, filosofia, ética, religião, arte, história e livros científicos (CALDIN, 2001, p. 3).

Tews (1962) conceituou Biblioterapia como um programa de atividades selecionadas, envolvendo material de leitura planejada, conduzido e controlado como tratamento, sob orientação do médico, para problemas emocionais ou outros. Deve ser ministrado por um bibliotecário habilidoso, profissionalmente treinado, dentro das propostas e finalidades prescritas (PEREIRA, 2000, p. 657).

Em seus estudos sobre a leitura, Caldin (2001, p. 8) verificou que os componentes biblioterapêuticos são: a catarse, o humor, a identificação, a introjeção, a projeção e a introspecção. Esses elementos fazem com que o paciente passe a ter um olhar diferenciado de seus problemas.

Shrodes realizou uma investigação detalhada da aplicação da Biblioterapia, citando autores como: Moore e seu estudo com delinqüentes juvenis, Menninger, que descreveu o Programa de Biblioterapia da Clínica Menninger, que proporcionava recreação e interação social entre os pacientes, encorajando o interesse e o contato com a realidade externa (CALDIN, 2001, p. 10). 
Maurice Barker, psicólogo clínico do Hopital Sainte-Justine. em Montreal, por meio de conferências na Université de Montreal e de um artigo publicado no periódico Documentation et Bibliotheques, na década de 70, mostrou preocupação com a leitura para jovens. No artigo "Bibliotheques et lectures pour jeunes", apresentou uma proposta de Biblioterapia para adolescentes. Lamentou o fato de os autores não se preocuparem muito com essa faixa etária, o que dificultou o uso do livro com finalidade terapêutica (CALDIN, 2001, p. 11).

Coelho (2000, p. 6) disse que é importante ajudar aos jovens leitores a se apropriarem do mundo, da cultura ou da poesia, através de livros, pois a leitura é um dos instrumentos fundamentais para a formação da cidadania, vista aqui como uma habilidade humana que permite o acesso do povo aos bens culturais já produzidos e registrados pela escrita e, portanto, como meio de conhecimento e crítica dos fatos históricos, científicos etc.

\section{A BIBLIOTERAPIA NO BRASIL}

No Brasil, essa prática começou, conforme expôs Almada (2003, p. 2), com projetos de extensão, realizados na década de 70. Entre eles destacaram-se: o da Universidade Federal do Rio Grande do Sul (UFRGS) com seu "Carro-Biblioteca", que levava, às vilas de Porto Alegre, livros de lazer e de auxílio às atividades escolares; o das "Caixas estantes,"que emprestava livros de literatura infantil para escolas públicas e particulares.

A Biblioterapia, sob o nome de "Hora do Conto," era um projeto de leitura de contos nos hospitais, asilos, creches e escolas. Existia, também, o "Livro de Cabeceira" que realizava sessões de leitura de contos em hospitais, com empréstimos de livros para os pacientes (ALMADA, 2003, p. 2).

Na década de 90, destacou-se a parceria entre a Fundação Biblioteca Nacional (FBN) e a Universidade Federal do Rio de Janeiro (UFRJ) que resultou na criação da "Casa da Leitura", gerenciada pelo Programa Nacional de Incentivo à Leitura (PROLER). Dele nasceu a proposta de uma biblioteca infantil, na qual seriam realizadas sessões de contos 
infantis, nas enfermarias pediátricas do Hospital Universitário Graffree Guinle (HUGG) (ALMADA, 2003, p. 3).

O projeto "Biblioteca Viva em Hospitais" iniciado em 2000 e desenvolvido com o apoio do Ministério da Saúde (MS), da Fundação Abrinq e do Citibank, capacitou representantes do Instituto Fernandes Figueira (IFF), do Instituto de Puericultura Martagão Gesteira (IPMG) e do Hospital Municipal Jesus (HMJ), para o desenvolvimento de sessões práticas de leitura de livros infantis em suas enfermarias pediátricas, realizadas por voluntários. No HMJ, o projeto, vinculado ao Núcleo de Projetos Especiais (NUPE) da Secretaria Municipal de Saúde do Rio de Janeiro, recebeu a doação de mil livros infantis, além de tapetes e almofadas para acomodar as crianças no horário da leitura.

Caldin (2002), Moreno (2003) e Pinheiro (2002) apresentaram experiências de implantação da Biblioterapia com crianças em hospitais, na seguinte ordem: no Hospital Universitário da Universidade Federal de Santa Catarina (UFSC), no Hospital Universitário Infantil Albert Sabin (HIAS), no Ceará e no Núcleo de Apoio a Criança com Câncer (NAAC), na Paraíba.

\section{CRITÉRIOS PARA APLICAR A BIBLIOTERAPIA}

Faz-se necessário observar que a aplicação da Biblioterapia pressupõe um estudo da comunidade na qual está inserida a Unidade de Saúde, do perfil do paciente quanto a sua idade, escolaridade, área de interesse, de forma a permitir que este se sinta preparado e aberto ao projeto, permitindo sua colaboração e participação e transformando momentos de ociosidade em oportunidade de agregar conhecimentos educacionais e culturais.

Esse momento de fragilidade é bastante acolhedor para derrubar as barreiras existentes sobre a leitura, por vezes, considerada aborrecida ou desinteressante. No ambiente hospitalar, os adolescentes encontram-se sem acesso aos meios de comunicação mais 
usuais como a televisão, rádio, Internet, cinema. Por outro lado, há uma aproximação maior entre eles e os que lhe dão suporte terapêutico naquele momento.

É, portanto, importante criar uma equipe engajada na escolha dos livros que vão compor o acervo, bem como na escolha dos aparatos que facilitarão o acesso aos livros tais como: carrinho para levar os livros para as enfermarias, estantes de aço para armazenamento do acervo.

Os profissionais para tratamento técnico e disponibilização dos livros, responsáveis para levar os livros até as enfermarias e os voluntários para sessão de leitura de histórias devem receber capacitação adequada e agirem em consonância com os profissionais de saúde no preparo do paciente para aceitar a Biblioterapia.

Os responsáveis pelas leituras deverão observar as seguintes recomendações, segundo Souza (2002, p. 5):

- Verificar o local, horário e as acomodações para a realização da leitura;

- Conhecer o público a que se destina;

- Ter o dom de contar história;

- Conhecer a história com absoluta segurança;

- Narrar com naturalidade sem afetação com voz clara e expressão viva;

- Sentir a história, mas sem deixar-se levar emocionalmente com a própria narrativa;

- Não perder o fio da meada quando estiver fazendo uso do livro ou outro elemento ilustrativo;

- Chegar ao final da história sem apontar a moral ou aplicar lições;

- Estar aberto para comentários após narrativa.

Remor (1997, p. 8) alertava que o encarregado da leitura deveria estar atento às necessidades dos pacientes para poder proporcionar uma assistência global não só a eles, mas também às pessoas interessadas como, por exemplo, membros da família e pessoas próximas aos pacientes, que desempenham papel fundamental como fonte de apoio e recurso. Contudo, deveria ser levado em consideração o estresse constante a que 
estão submetidos os adolescentes em conseqüência da enfermidade, podendo eles optar por participar ou não da Biblioterapia.

Diante do exposto, haverá necessidade de elaborar critérios para a escolha da Unidade Hospitalar, onde será desenvolvido um projeto piloto de Biblioterapia.

Será condição para escolha do acervo identificar, através de um prognóstico, as condições de saúde dos pacientes, analisando os seguintes aspectos indicados por Fontenele (2000, p. 10): o diagnóstico da patologia, seu tratamento, o tempo de hospitalização, a possibilidade de cura ou de morte. Através desses dados, será possível selecionar as condições necessárias para desenvolver a Biblioterapia (PINHEIRO, 2003, p. 4).

Para aplicação da Biblioterapia, Borba sugere:

Apesar dos adolescentes variarem muito em seus interesses de leitura, eles tendem a se interessar constantemente por livros de capa de papel, em vez de livro de capa dura, por livros recomendados por seus amigos, em vez dos indicados por seus professores, e no conteúdo do primeiro parágrafo, em vez do tamanho das letras e número de ilustrações (BORBA, 2000, p. 12).

O trabalho com voluntários adolescentes será recomendável por proporcionar a aproximação de adolescentes em diferentes condições de vida.

O relatório final da $11^{\text {a }}$ Conferência Nacional de Saúde, sob o tema Efetivando o SUS: acesso, qualidade e humanização na atenção à Saúde, com controle social, em seu item 200, evidencia a:

promoção de parcerias, visando uma cooperação técnica entre gestores, prestadores de serviço e instituições de ensino para ampliar o conhecimento sobre temas vinculados a saúde e sua divulgação para a sociedade e estabelecer parcerias com universidades para implementação das ações de educação em saúde junto às populações

(CONFERÊNCIA..., 2002, p. 162).

Por ocasião da avaliação da implantação da Biblioterapia, a parceria entre médicos, biblioterapeutas e pacientes deverá ser valorizada com intuito de observar os fatores que dizem respeito à melhoria de saúde física dos pacientes (FERNANDEZ VASQUEZ, 2002, p. 660). 
Moreno (2003, p. 166) apresentou, em seu estudo, um modelo de questionário de avaliação, que foi adaptado para uso neste trabalho (ver Anexo I). A escolha desse modelo teve base no êxito obtido na sua aplicação em projetos de Biblioterapia com crianças, com objetivo de estimular a leitura, para apressar a cura de adolescentes, dados os seguintes passos:

-Aplicação da Biblioterapia em Unidade(s) Hospitalar(es) da Rede Municipal de Saúde do Rio de Janeiro onde já exista algum tipo de trabalho desenvolvido pela Gerência de Saúde do Adolescente;

-Engajamento da equipe médica na aplicação da Biblioterapia, que traz consigo um elemento de humanização ao tratamento dispensado aos adolescentes;

-Montagem das equipes de profissionais de áreas correlatas à aplicação da Biblioterapia, ou seja, bibliotecários, psicólogos, assistentes sociais entre outros;

-Formação de acervo para a aplicação da Biblioterapia, direcionada para adolescentes;

-Aquisição do material de suporte para guarda e circulação do acervo a ser utilizado na Biblioterapia;

-Conhecimento das atividades hospitalares e seus respectivos horários para melhor adequar a aplicação da Biblioterapia;

- Integração de voluntários adolescentes no programa de Biblioterapia, atuando como leitores para os adolescentes pacientes, que deverão ser recrutados nas escolas da Rede particular, oferecendo a oportunidade ao aluno, da rede privada, de conhecer a realidade dos adolescentes de classes sociais menos favorecidas e ao mesmo tempo, promover a integração e troca de experiências entre eles. Todas as atividades deverão ser avaliadas através de formulário. Os resultados auxiliarão na implementação e continuidade do projeto e auxiliarão na divulgação dos resultados obtidos com a implantação do projeto.

\section{CONSIDERAÇÕES FINAIS}

Como resultado imediato, é esperado que, com a aplicação da Biblioterapia, haja uma redução do estresse do adolescente em função de seu estado de saúde e da sua incapacidade de locomoção.

(C) Revista Digital de Biblioteconomia e Ciência da Informação, Campinas v.3, n. 2, p. 112-126, jan.jun. 2006-ISSN: 1678-765X. 121 
Com a aplicação da Biblioterapia, nas enfermarias de adolescentes das Unidades Hospitalares da Rede Municipal de Saúde do Rio de Janeiro, há o desejo de, ao final do período de internação, devolver ao paciente o prazer de viver, através de identificação com as fontes de leitura e, conseqüentemente, aumentar a qualidade de vida, bem como estimular seu desenvolvimento integral, contribuindo para expandir seus conhecimentos e auxiliar no processo escolar.

O projeto pretende promover a integração da equipe de profissionais em torno do objetivo comum do projeto de Biblioterapia, contribuindo para humanização do atendimento médico nas Unidades Hospitalares;

O incentivo à leitura, como instrumento educativo e de lazer, pode trazer efeitos positivos tanto para os adolescentes pacientes quanto para os adolescentes leitores voluntários.

\section{REFERÊNCIAS}

ALMADA, M. Social: compromisso do ser bibliotecário. In: JORNADA NORTENORDESTE DE BIBLIOTECONOMIA E DOCUMENTAÇÃO, 4., 2003, Recife . Anais ... Recife: UPBE, 2003. Disponível em:

$<$ http:// www.biblio.ufpe.br/apbpe/relato/trabalhos.htm>. Acesso em: 14 jun. 2005.

BORBA, M. S. A. Adolescência e leitura: a contribuição da escola e da biblioteca escolar.In: CONGRESSO BRASILEIRO DE BIBLIOTECONOMIA E DOCUMENTAÇÃO, 19., 2000, Porto Alegre. Anais ... Porto Alegre: PUCRS, 2000. CD-Rom.

BRASIL. Lei 8069 de 13.07.1990. Estatuto da criança e do adolescente. Diário Oficial [da] República Federativa do Brasil, Brasília, DF, 13 jul. 1990. Disponível em: $<$ http://www.planalto.gov.br/ccivil_03/Leis/L8069.htm>. Acesso em: 20 jun. 2005.

CALDIN, C. F. Biblioterapia para crianças internadas no hospital Universitário da UFSC: uma experiência. Encontros de Bibliotecários. Revista de Biblioteconomia e Ciência da Informação, Florianópolis, n. 14, out. 2002. Disponível em:

$<$ www.encontros-bibli.ufsc.br/Edicao 14/clarice.pdf $>$.

Acesso em: 14 jun. 2005. 
CALDIN, C. F. A leitura como função terapêutica: biblioterapia. Encontros de Bibliotecários. Revista de Biblioteconomia e Ciência da Informação, Florianópolis, n. 12, dez. 2001. Disponível em: <http://www.encontrosbibli.ufsc.br/Edicao 12/caldin.pdf>. Acesso em: 14 jun.2005.

COELHO, R. W. da C. Biblioteca e leitura: experiência interdisciplinar com profissionais da educação. In: CONGRESSO BRASILEIRO DE BIBLIOTECONOMIA E DOCUMENTAÇÃO, 19., 2000, Porto Alegre. Anais ... Porto Alegre: PUCRS, 2000. CD-Rom.

CONFERÊNCIA NACIONAL DE SAÚDE, 11., 2000, Brasília. Relatório final. Brasília: Ministério da Saúde, 2000.

FERNANDEZ VASQUEZ, M. S. A.; PEREIRA, M. M. G. A autenticidade no modelo brasileiro de um programa de implantação de biblioterapia para os mutilados, vítimas da violência urbana: uma proposta de pessoas designadas como portadoras de necessidades especiais. In: INTEGRAR. CONGRESSO INTERNACIONAL DE ARQUIVOS, BIBLIOTECAS, CENTROS DE DOCUMENTAÇÃO, MUSEUS, 1., 2002, São Paulo. Anais ... São Paulo: Imprensa Oficial do Estado, 2002. p. 655-62.

FERREIRA, D. T. Biblioterapia: uma prática para o desenvolvimento pessoal. ETD. Educação Temática Digital, Campinas, v. 4, n. 2, p. 35-47. jun. 2003. Disponível em: $<$ http://www.bibli.fae.unicamp.br/etd/biblioterapia.pdf $>$. Acesso em: 15 jun. 2005.

FONTENELLE, M. de F. S. A biblioterapia no tratamento do câncer infantil. In: CONGRESSO BRASILEIRO DE BIBLIOTECONOMIA E DOCUMENTAÇÃO, 19., 2000, Porto Alegre. Anais ... Porto Alegre: PUCRS, 2000. CD-Rom.

MORENO, R. L. R. et al. Contar histórias para crianças hospitalizadas: relato de uma estratégia de humanização. Pediatria,. n. 25, v. 4, 2003. p. 164 - 169. Disponível em:< http://www.pediatriasaopaulo.usp.br/index.php?p=html\&id=593> Acesso em: 15 jun. 2005.

PARDINI, M. A. Biblioterapia! Encontro perfeito entre o bibliotecário, o livro e o leitor no processo de cura através da leitura. Estamos preparados para essa realidade? In: SEMINÁRIO NACIONAL DE BIBLIOTECAS UNIVERSITÁRIAS, Recife, 12, 2002.Anais... Disponível em:

$<$ http://www.sibi.ufrj.br/snbu/snbu2002/oralpdf/87.a.pdf $>$. Acesso em: 15 jun. 2005.

PEREIRA, M. M. G. Biblioterapia e leitura crítica para a formação da cidadania com os alunos do Instituto dos Cegos da Paraíba Adalgisa Cunha. In: CONGRESSO BRASILEIRO DE BIBLIOTECONOMIA E DOCUMENTAÇÃO, 19., 2000, Porto Alegre. Anais ... Porto Alegre: PUCRS, 2000. CD-Rom.

PESSINI, L. Humanização da dor e do sofrimento humano na área da saúde. In: PESSINI, Leo; BERTRANCHI. L. (Orgs.). Humanização e cuidados paliativos. São Paulo: Loyola, 2004. p. 11-30. 
PINHEIRO, E. G. et al. Abra os olhos e também o coração: a história do projeto reviver - biblioterapia com crianças portadoras de câncer. João Pessoa, 2002. Disponível em: $<$ http://www.prac.ufpb.br/anais/anais/educacao/reviver.pdf $>$. Acesso em : 14 jun. 2005.

REMOR, E. A. Contribuições do modelo psicoterapêutico cognitivo na avaliação e tratamento psicológico de uma portadora de HIV. Psicol. Reflex. Crit., v. 10, n. 2, Porto Alegre, 1997. 11p. Disponível em:

$<$ http://www.scielo.br/scielo.php?script $=$ sci arttext\&pid $=$ S010279721997000200005\&lng=pt\&nrm=isso $>$ Acesso em: 14 jun. 2005.

SOUZA, K.; BOTELHO, R. A biblioterapia no tratamento de crianças enfermas. Revista Bibliomar, Maranhão, v. 2, n. 2, 2002. Disponível em:

$<$ http://www.ufma.br/canais/bibliomar/edic_ant.htm>. Acesso em: 14 jun. 2005.

TEWS, R. M. Introduction. Library Trends, v. 11, n. 2, p. 97- 105, 1962. 


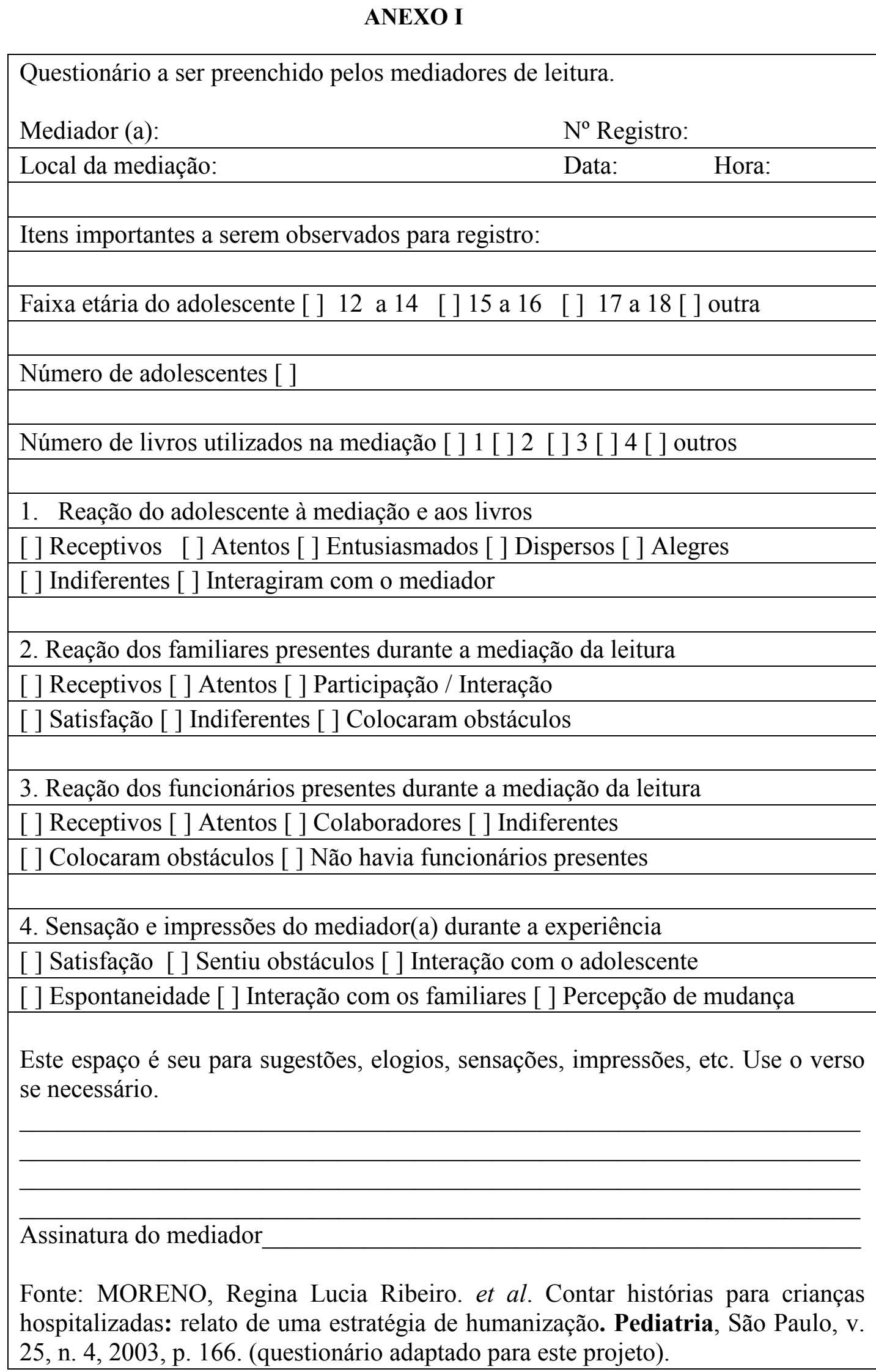




\section{Gizele Ribeiro}

Especialista em Informação Cientifica e Tecnologica em Saúde - CICT/FIOCRUZ/RJ Especialista em Gestão de Recursos Humanos - UGF

Bibliotecária UNIRIO

Diretora da Divisão de Biblioteca da Coordenação de Desenvolvimento de Recursos Humanos da Secretaria Municipal de Saúde gribeiro@rio.ri.gov.br

Artigo aceito para publicação em janeiro de 2006. 